\title{
SOBRE AS ESTRUTURAS DE CONHECIMENTO A PRIORI EM KANT E Piaget: UM ENSAIO
}

\author{
ON A PRIORI KNOWLEDGE STRUCTURES IN KANT AND PIAGET: AN ESSAY
}

OI: $\underline{10.23926 / R P D .2526-2149.2020 . v 5 . n 3 . p 2016-2032 . i d 814 ~}$

\author{
José Galúcio Campos \\ Doutor em Educação em \\ Ciências e Matemática \\ (UFMT) \\ Professor no Instituto \\ Federal do Amazonas, \\ Campus Manaus Centro \\ (IFAM/CMC) \\ jose.campos@ifam.edu.br
}

\section{Daniel Richardson de \\ Carvalho Sena}

Mestre em Ciências do

Ambiente e Sustentabilidade

na Amazônia (UFAM)

Professor no Instituto

Federal do Amazonas,

Campus Manaus Centro

(IFAM/CMC)

daniel.sena@ifam.edu.br
Resumo: Este ensaio pode ser visto como uma contribuição teórica cujo objetivo é indicar as diferenças entre as estruturas de conhecimento a priori (apriorismo) nos construtivismos de Kant e Piaget. Para tanto, utilizamos como método a análise bibliográfica, tendo como texto de base a Crítica da Razão Pura e a Epistemologia Genética, mas, também, levamos em consideração textos de comentadores de Kant e de alguns e teóricos da educação. Disto resulta que: a) a concepção de estrutura a priori é diferente para ambos, para Kant elas são estáticas, para Piaget são dinâmicas e evoluem ao longo da vida; b) que não se pode reduzir um construtivismo ao outro, mesmo que somente do ponto de vista prático. Ao final, c) mostramos a luz do exposto, como o modelo pedagógico apriorístico pode ser um inconveniente se praticado literalmente conforme seus pressupostos teóricos, em especial porque minimiza o papel do professor e da escola na formação educacional.

Palavras-chave: Epistemologia. Construtivismo. Pedagogia.

Abstract: This essay can be take into account of a theoretical contribution such as aims to indicate the differences between a priori knowledge structures (apriorism) in Kant and Piaget's constructivisms. For that, we used bibliographic analysis as a method, having the Critique of Pure Reason and Genetic Epistemology such as the basics texts, in addition, we take into account some Kant's commentators and some education theorists. It follows that: a) the concept of a priori structure is different for both, for Kant they are static, for Piaget they are dynamic and change throughout the life; b) that one cannot reduce one constructivism to another, even if only from a practical point of view. At the end, c) we show the light of the above, how the a priori pedagogical model can be an inconvenience if practiced literally according to its theoretical assumptions, especially because it minimizes the role of the teacher and the school in educational training.

Keywords: Epistemology. Constructivism. Pedagogy. 


\section{INTRODUÇÃO}

Este ensaio tem o objetivo de estabelecer o papel ocupado pelas estruturas a priori do conhecimento nas epistemologias de Kant e Piaget por meio de aproximações e afastamentos do que escreveram esses autores sobre o tema. A estrutura de conhecimento a priori é algo caro à epistemologia (e à gnosiologia), seja para um ou outro pensador.

O apriorismo vem de a priori e significa supor a existência de categorias de entendimento universais como por exemplo: objeto, causalidade, espaço e tempo. Estas categorias já se encontram no sujeito antes da experiência. Não é, portanto, um tipo de conhecimento que se adquire com a experiência, mas, com efeito, o sujeito as impõe à experiência para lhe ordenar dados sensoriais e, sobretudo, conceber a experiência como um meio válido para obter conhecimento.

Nesse aspecto, a epistemologia genética piagetiana não é apriorista inteiramente, tem sim uma componente apriorista fazendo referência as estruturas mentais inatas (a priori) de pensamento geneticamente adquiridas. Então, como veremos, Kant era eminentemente apriorista; Piaget, não. E, aproveitando o ensejo, ao falarmos de modelo pedagógico apriorista ou não-diretivo, queremos remeter o leitor a um modelo cujo fundamento é o apriorismo kantiano, termo este que ficará claro mais adiante no texto.

Kant, segundo Castañon (2015), pode ser considerado o pai do construtivismo na modernidade. O próprio Piaget admitiu ser influenciado por Kant. Acontece que o construtivismo piagetiano, exerceu e ainda exerce grande influência na educação. Não somente de quando em quando, professores e teóricos da educação veem na figura de Piaget um grande pedagogo. Conforme Gaspar (2014), em terrae brasilis, o movimento construtivista foi muito forte na década de 1980, mas nos dias atuais, ainda é possível vislumbrá-lo.

Vejamos, por exemplo, os Parâmetros Curriculares Nacionais, os PCN’s (BRASIL, 1997). Esse documento sugere ao professor contextualizar/problematizar os conteúdos curriculares com o fim de concretizá-los através de situações reais e familiares à realidade imediata dos alunos (ROCHA, 2019). Essa é uma face do construtivismo piagetiano, consequência direta dos estágios (estádios) do desenvolvimento cognitivo, conforme postulado pelo próprio Piaget (2007).

Continuando, constatamos a mesma situação nas Diretrizes Curriculares Nacionais, as DCN's (BRASIL, 2010). Estas diretrizes versam sobre o ensino por competência ${ }^{1}$ que nos

\footnotetext{
${ }^{1}$ Consta também o ensino por competência nos Parâmetros Curriculares Nacionais. 
remete ao aprender fazendo e ao aprender a aprender. Ambos são faces do construtivismo piagetiano também. Aqui a função pedagógica é um volver-se da lógica inerente ao conteúdo curricular à lógica do pensamento do aluno, como ressaltado Gaspar (2014).

Por fim, recentemente foi aprovada a Base Nacional Comum Curricular, a BNCC (BRASIL, 2016). Embora este seja um documento muito criticado devido à ausência explícita de bases teóricas, como o construtivismo, por exemplo, ainda é um documento que fala de aprendizagem por competências e habilidades e, a contextualização dos conteúdos curriculares. Como já vimos, essas são faces do construtivismo piagetiano.

Becker (2001) chama a atenção de que o modelo pedagógico construtivista piagetiano (ou dialético) tem base epistemológica diversa do modelo não-diretivo ou apriorístico. Este repousa no apriorismo (inatismo), ao passo que aquele, ancora-se na epistemologia genética. Entretanto, não é raro professores e pesquisadores confundirem um com o outro.

Em síntese, a acentuada influência do construtivismo piagetiano na educação nacional, além dos equívocos conceituais ante os modelos pedagógicos construtivista e o apriorista, são as duas razões pelas quais justificamos a escrita deste ensaio e, consoante às especificidades do apriorismo, lançamos as seguintes questões: (a) teria Kant e Piaget o mesmo entendimento sobre as estruturas a priori do conhecimento? (b) ante os aspectos teórico e concreto, é possível reduzir o apriorismo piagetiano ao kantiano? (c) qual o papel do professor diante desses construtivismos?

$\mathrm{O}$ modus faciendi de responder as questões acima consistiu em realizar um cotejo entre Kant e Piaget em face ao grau ou tipo de apriorismo defendido por ambos. Para tanto, fizemos uma pesquisa bibliográfica tendo como textos de base a Crítica da Razão Pura e Epistemologia Genética de Kant e Piaget, respectivamente.

Este ensaio, sobretudo, é voltado para professores e alunos sem expertise em epistemologia e filosofia da educação, mas que desejam apropriar-se dos elementos teóricos básicos que sustentam os construtivismos kantiano e piagetiano. A contribuição oferecida aqui é de natureza teórica e não original quando vista de per se. No entanto, há de se ter em mente que o tema abordado ainda não é de domínio geral, mesmo para professores e alunos.

\section{MÉTODO}

Neste ensaio fizemos uma pesquisa bibliográfica (GIL, 2010) tendo como textos de base os livros a Crítica da Razão Pura de Immanuel Kant (1983) e, a Epistemologia Genética de 
Jean Piaget (2007). Paralelamente, outros textos foram sendo adicionados, alguns mais por necessidade de citação do que em atenção ao problema que convém ao ensaio.

Em relação ao construtivismo piagetiano, o livro Seis Estudos de Psicologia, de Piaget, de 1999, ajudou no melhor entendimento das fases do desenvolvimento cognitivo e, nos fatores que influenciam seu desenvolvimento, ambos expostos de modo mais didático que de costume, pois Piaget é um autor de difícil leitura.

Ainda sobre o construtivismo piagetiano, os textos do autor Fernando Becker foram muito importantes. A exposição sistemática e sintética que esse autor faz dos elementos teóricos centrais do construtivismo piagetiano cobre quase que completamente o tema abordado. Embora sintética, é uma exposição muito didática. No aspecto epistemológico, demos especial atenção ao seu artigo de 2014: Abstração pseudo-empírica e reflexionante.

Ao lado de Fernando Becker, tivemos o autor Alberto Gaspar com seu livro intitulado Atividades Experimentais no Ensino de Física publicado em 2014. Apesar de o livro não está voltado para construtivismo piagetiano, outrossim, ao socio-construtivismo de Vigotski, no capítulo 3, Gaspar apresenta uma explanação muito didática sobre o desenvolvimento da mente humana por meio da teoria piagetiana. Além disso, o autor avança e, no capítulo 4, indica como foi a recepção do construtivismo piagetiano na educação, algo que interessa a este ensaio.

Kant é também um autor de difícil leitura, e neste aspecto o livro O Pensamento de Kant de Georges Pascal publicado em 2001, apresenta a explicação das Estética e Analítica transcendentais de modo mais simples, direto e de mais fácil entendimento. O Vocabulário de Kant, de Jean-Marie Vaysse, por sua vez, mostrou-se muito útil dando o significado preciso dos termos usados na Crítica.

No mais, no artigo Kant e Adorno: educação e autonomia dos autores Victor Silva e Daniel Sena, não está voltado especificamente para o tema desse ensaio, no entanto, eles abordam tema correlato e, trazem uma ilustrativa explicação sobre a revolução copernicana feita por Kant na filosofia.

\section{CONSTRUTIVISMO KANTIANO OU CRITICISMO}

No advento da modernidade (século XVI), duas correntes filosóficas se destacaram na discussão sobre a origem do conhecimento humano: o empirismo, afirmando que a experiência é a sua fonte, pois a mente humana seria uma estrutura vazia a ser preenchida por conteúdos empíricos; e o racionalismo, que defendia a tese de que possuímos ideias inatas, que fazem 
parte de nossa estrutura cognitiva e garantem a construção do conhecimento apenas pelo uso da razão.

No século XVIII, o filósofo alemão Immanuel Kant (1724-1804), em sua obra Crítica da Razão Pura (publicada em 1871), desenvolve uma teoria chamada de apriorismo ou transcendentalismo, afirmando que o conhecimento é construído pela união da experiência com a razão.

Conforme Vaysse (2012), na filosofia kantiana a expressão a priori indica algo que não se origina da experiência, em oposição a a posteriori, sinônimo de empírico; já o termo transcendental "designa um uso a priori do conhecimento e explica como é possível uma necessária submissão dos objetos a conceitos puros bem como uma aplicação desses conceitos aos objetos" (VAYSSE, 2012, p. 76).

$\mathrm{Na}$ filosofia do conhecimento kantiana existe a predominância de elementos a priori. Todavia, para haver conhecimento é necessária também a existência de conteúdos sensíveis. Para Kant, a estrutura cognitiva humana possui duas faculdades compostas por elementos $a$ priori que são responsáveis pela construção do conhecimento: a sensibilidade e o entendimento. São a priori as formas da sensibilidade, espaço e tempo, e, os conceitos ou categorias do entendimento. As formas da sensibilidade constituem as condições de apreensão sensíveis dos objetos; os conceitos compõem as regras que possibilitam pensar o objeto (KANT, 1983).

Segundo Mondin (2009), na filosofia do conhecimento de Kant as formas a priori espaço e tempo fazem parte da nossa estrutura mental. São esquemas vazios em si mesmos, presentes em toda experiência e que se tornam perceptíveis no ato em que formam um conteúdo empírico.

Para Kant (1983), a sensibilidade, ou faculdade das intuições, através de suas formas $a$ priori permite a representação dos objetos sensíveis: o espaço é a forma das experiências ou percepções externas e o tempo é a forma das vivências ou percepções internas. Por meio destas formas encontra-se o que pode ser conhecido a priori na intuição. Porém, apenas com os dados oriundos da intuição não é possível a construção do objeto do conhecimento, é necessário que esses dados apreendidos sejam sintetizados pela atividade do entendimento.

Diferentemente da sensibilidade, que intui os dados da experiência, o entendimento irá pensá-los por meio de suas formas a priori, as categorias. Na segunda parte da Crítica da Razão Pura, intitulada Lógica transcendental, Kant (1983) apresenta as categorias do entendimento ou ações do pensamento puro, dividindo-as em quatro grupos de três: Categorias de Quantidade (Unidade, Pluralidade e Totalidade); Categorias de Qualidade (Realidade, Negação e 
Limitação); Categorias de Relação (Inerência e Substância, Causalidade e dependência e Comunidade) e Categorias de Modalidade (Possibilidade - Impossibilidade, Existência - Não Ser e Necessidade - Contingência).

Após a exposição das doze categorias, é preciso demonstrar como a intuição sensível acolhe as formas a priori, isto é, como os conceitos que não nascem da experiência se aplicarão a ela. Tal processo ocorre por meio de esquemas. Segundo Kant (1983), o esquema é a representação de um processo geral graças ao qual a imaginação oferece sua imagem a um conceito. As categorias só serão utilizáveis e só poderão representar um objeto se forem esquematizadas. O esquematismo kantiano possui a função de eliminar a heterogeneidade dos dois elementos da síntese, sendo geral como a categoria e temporal como o conteúdo da experiência.

Segundo Vaysse (2012), os esquemas são produzidos pela imaginação, uma faculdade também intermediária entre a sensibilidade e o entendimento que se relaciona com seus elementos a priori, garantindo uma intercessão entre a receptividade da sensibilidade e a espontaneidade do entendimento.

O processo realizado pela imaginação se dá através de um elemento puro, comum às intuições e aos conceitos, capaz de conciliá-los. Este elemento puro é o tempo.

\begin{abstract}
Como a condição formal do múltiplo do sentido interno, por conseguinte da condição de todas as representações, o tempo contém na intuição pura um múltiplo a priori. Ora, uma determinação transcendental do tempo é homogênea à categoria (que constitui a unidade de tal determinação) na medida em que é universal e repousa numa regra a priori. Por outro lado, a determinação do tempo é homogênea ao fenômeno, na medida em que o tempo está contido em toda representação empírica do múltiplo. Logo, será possível uma aplicação da categoria a fenômenos mediante a determinação transcendental do tempo que, como o esquema dos conceitos do entendimento, media a subsunção dos fenômenos à primeira. (KANT, 1983, p. 104)
\end{abstract}

Percebemos que os esquemas são determinados pelo tempo e constituem conceitos sensíveis de objetos de acordo com uma categoria determinada. Existem, portanto, vários tipos de esquemas, segundo os quatro grupos de categorias.

Kant explica que no esquema da categoria de quantidade é o número, e ele não é senão "a unidade da síntese do múltiplo de uma intuição homogênea em geral, mediante o fato de que produzo o próprio tempo na apresentação da intuição" (KANT, 1983, p. 106).

Em relação às demais categorias, Pascal apresenta de forma objetiva seus respectivos esquemas:

O conteúdo do tempo é o esquema da qualidade; o tempo preenchido pela sensação corresponde à categoria da realidade; o tempo vazio corresponde à categoria da negação. Do ponto de vista da relação, o esquema da substância é a permanência do 
real no tempo; o da causalidade, a sucessão constante; o da ação recíproca, a simultaneidade regular. Enfim, as categorias da modalidade correspondem: a existência virtual no tempo (possibilidade), a existência atual no tempo (realidade), a existência perpétua no tempo (necessidade). (PASCAL, 2001, p. 76)

A síntese dos dados sensíveis pelo entendimento ocorre de forma temporal, por meio dos esquemas a priori que organizam os conteúdos apreendidos por meio da experiência. Entretanto, não é possível apreender a essência das coisas, mas apenas o que é dado pelos sentidos. Conforme Sena e Silva (2015), na perspectiva gnosiológica kantiana a estrutura cognitiva humana através das informações dadas pelos sentidos se submete a uma atividade conceitual a priori da razão, porém, seu uso legítimo limita-se ao que pode ser apreendido sensorialmente. Assim, qualquer intento ou aplicação fora deste limite sensível será sempre ilícito. Para haver conhecimento, portanto, é necessário que existam elementos sensíveis e elementos inteligíveis, como expressou Kant: "Pensamentos sem conteúdo são vazios, intuições sem conceitos são cegas" (KANT, 1983, p. 57).

O objeto do conhecimento na teoria do conhecimento de Kant chama-se fenômeno, constituído por sua matéria, dada pela da sensibilidade; e por sua forma que advém do entendimento. Segundo o apriorismo kantiano, só será possível conhecer algo que possua elementos empíricos, o que ultrapassa os limites da experiência possível é chamado de númeno, as essências correspondentes às realidades metafísicas.

Destarte o exposto, na filosofia especulativa kantiana o sujeito é ativo na construção do conhecimento, pois seu objeto é determinado a priori pela própria natureza da faculdade de conhecer, porém, sempre reportado aos dados intuídos pela experiência. Para Kant, "a razão não percebe senão aquilo que ela mesma produz segundo o seu próprio projeto" (KANT, 1983, p. 11), ou seja, é o sujeito que no ato de conhecer coloca no objeto os elementos a priori contidos nele mesmo. Nessa perspectiva não é a estrutura cognitiva humana que se conforma às coisas, mas são as coisas que se conformam a ela.

\section{CONSTRUTIVISMO PIAGETIANO OU EPISTEMOLOGIA GENÉTICA}

A epistemologia genética é um desenvolvimento teórico (e metodológico) realizado por Jean Piaget (1860-1980), cujo objetivo é explicar e investigar como o sujeito constrói seu próprio conhecimento e se desenvolve mentalmente, desde o nascimento até a fase adulta (PIAGET, 2007).

Para tanto, Piaget (1999) postulou que, embora o desenvolvimento mental ocorra continuamente, é possível identificar que esse processo acontece por distintas etapas ou fases. 
A primeira fase, a sensório-motora, ocorre entre 18 e 24 meses. A segunda, a pré-operatória, entre 2 e 7 anos. A terceira conhecida como operatório-concreta, ocorre entre os 7 aos 12 anos. E finalmente a quarta, chamada de operatório formal, acontece entre 12 e 15 anos.

Não convém a este ensaio explicar com detalhes os processos que inerem a cada uma dessas fases, isso já é algo vastamente discutido na literatura educacional. Mas cabe ressaltar que, como consequência da programação genética, cada fase tem uma distinta estrutura cognitiva ou esquema mental (GASPAR, 2014). Isto sugere que há algo inato ou a priori no sujeito - geneticamente programado. Mas, como veremos, esse apriorismo é distinto do kantiano, como exposto na seção anterior.

Ainda em relação as fases de desenvolvimento, Gaspar (2014) explica que a epistemologia genética sofreu muitas críticas após verificação empírica de que, mesmo os adultos, não estariam no estágio formal de desenvolvimento cognitivo. Isso fez com que Piaget declarasse que o grau de cognição, bem como as idades supraditas nas fases de desenvolvimento, não são estanques; outrossim, são estimativas (BECKER, 2001; 2013).

Para entender o porquê, é suficiente ter em mente os quatro fatores que concorrem ao desenvolvimento desses esquemas mentais (PIAGET, 1999; 2007): a maturação (genético), as experiências de vida (influência do meio físico), a transmissão social (influência do meio social) e a equilibração (equilíbrio de fluxos).

Não é forçoso observar que na epistemologia genética há uma tensão entre a programação genética e a influência do meio para constituição do desenvolvimento cognitivo e, por conseguinte, do desenvolvimento da inteligência. Contudo, supor que a inteligência se desenvolve posteriormente ao desenvolvimento cognitivo, e por etapas, já distingue a epistemologia genética das ditas epistemologias tradicionais, como empirismo e o racionalismo apriorista.

Todavia, isso não significa que Piaget a tenha concebido à revelia do empirismo de Locke, Berkeley e Hume, bem como do inatismo de Descartes e/ou do apriorismo de Kant. Pelo contrário. Como vemos em Piaget (2007) e reforçado por Becker (2013), o construtivismo piagetiano se pretende um caminho do meio, postulando que o conhecimento não está pronto nem no objeto, com supunham os empiristas e, nem no sujeito, como dito pelos aprioristas. Com efeito, Piaget retoma do empirismo a importância do objeto e do apriorismo os esquemas mentais geneticamente programados. 
Piaget era biólogo de formação e emprestou da biologia uma série de termos técnicos para explicar como se desenvolve a cognição e definir a inteligência (PIAGET, 2013). Discutiremos, aqui, somente aqueles que convêm à realidade desse ensaio.

Iniciamos a exposição com a autorregulação. Autorregulação é um importante conceito da epistemologia genética; conceito esse que nomeia e explica a capacidade do sistema vivo em se adaptar às situações exteriores, bem como, de modificá-las se necessário for. Assim, duas são as funções de importância magna à adaptação do sujeito ao meio, quais sejam: a assimilação e a acomodação (BECKER, 2013; PIAGET, 2007). Dizemos então que, autorregulação é assimilação mais acomodação.

Assimilação é um esquema de ação pelo qual o sujeito busca se apropriar do objeto de conhecimento ante os esquemas mentais que possuem naquele momento específico de apreensão do objeto. Este processo torna-se tão mais eficiente quanto forem as múltiplas vivências (experiências prévias) do sujeito com o objeto ou com objetos semelhantes (PIAGET, 2007; 2013).

A acomodação é quando o sujeito transforma os esquemas de assimilação devido aos desafios impostos pelo meio, portanto é uma ação complementar à assimilação (BECKER, 2013; CASTAÑON, 2015; PIAGET, 2007). Com efeito, o sujeito nunca se submete passivamente à ação do meio, embora nessa condição, faz-se necessário modificar o ciclo de assimilação. É isso que torna os esquemas de assimilação mais robustos e complexos deixando o sujeito cada vez mais apto para apreender camadas mais profundas e complexas da realidade (PIAGET, 2007; 2013).

As estruturas ou esquemas de ação são endógenos, ou seja, são internos ao sujeito. Isso pode sugerir, assim como no apriorismo kantiano, que todas as possibilidades para conhecer já estão prontas no sujeito. Não é bem essa a tese da epistemologia genética. Em tempo algum podemos reduzí-la a esquemas internos, subjetivos, particulares e sem relação com o meio. Já vimos, afinal, que a influência do meio físico e a transmissão cultural são fatores relevantes ao desenvolvimento da cognição (GASPAR, 2014; PIAGET, 1999).

Indo um pouco mais a fundo nessa questão. De Castañon $(2015$, p. 217) retiramos a seguinte argumentação:

Quando uma criança ou qualquer pessoa tem uma experiência, ela primeiramente tenta a assimilar em seus esquemas existentes. No entanto, se essa experiência resiste ao enquadramento, se suas predições sobre fenômenos (objetos e do meio)2

\footnotetext{
${ }^{2} \mathrm{O}$ parêntese é por nossa conta.
} 
semelhantes são repetidamente desmentidas pela ação no mundo, prevalece a tendência de o esquema se modificar de modo a acomodar-se a essa experiência.

Pois bem, pelo excerto acima, podemos inferir que Piaget é um realista. Ora, se há a resistência do enquadramento dos objetos e do meio, pelos esquemas de assimilação, é porque o objeto (o real) é independente da intenção do sujeito, fato este admitido por Piaget no seu livro Epistemologia Genética (PIAGET, 2007), por exemplo.

Outra situação em que Piaget reafirma a importância do meio externo é quando inicia a discussão sobre o realismo infantil em A Construção do Real na Criança (PIAGET, 2005). Aqui, uma vez mais, ele deixa claro que não nega a independência dos objetos em relação ao sujeito e, esclarece, com precisão, a diferença entre realismo e objetivismo (PIAGET, 2005).

Certo que a acomodação é um esquema interno, portanto, subjetivo e, consequentemente particular (individual), mas em tempo algum é independente do mundo. Admitir que os esquemas de ação independem do mundo, consiste em encerrar o construtivismo piagetiano numa versão radical e solipsista, tal qual o construtivismo de Von Glasersfeld (CASTAÑON, 2015). É digno de nota, e esse é o ponto, que Piaget não nega que há um mundo objetivo, mas não é objetivista. Não nega, também, a importância das estruturas cognitivas dadas a priori, mas não é solipsista.

A tese piagetiana ante a construção do conhecimento é a seguinte: não há conhecimento pronto nem no objeto e nem no sujeito, mas antes, deve haver uma relação dialética entre ambos para construí-lo e, antes dessa dialética acontecer, não há nem sujeito e nem objeto (BECKER, 2013). Em um primeiro momento, essa parece ser uma tese radical. Contudo, ela serve para pontuar que não há sujeito sem objeto e, nem objeto sem sujeito.

Podemos vislumbrar o valor dessa afirmação observando o papel ocupado pela abstração na epistemologia genética. Isso ajuda a reforçar a tese de que não convinha a Piaget postular sujeitos ou objetos absolutos, outrossim, argumentar em prol de uma relação dialética entre ambos.

Pois bem, Piaget discrimina três tipos de abstrações (BECKER, 2013): abstração empírica ou aristotélica, abstração reflexionante e a abstração pseudo-empírica. Esta última é um tipo de abstração reflexionante, mas discriminamo-la por motivo que explicaremos logo mais.

Conforme Becker (2014) e Terribile (2019) nomeamos por abstração empírica o modo de conhecer cujo as informações que retiramos do objeto são suas características observáveis. Portanto, ela volta-se para o objeto. A abstração reflexionante retira qualidades das ações ou 
das coordenações das ações que são realizadas pelo sujeito ante a apreensão do objeto. Portanto, é algo interno, voltando-se para o sujeito.

Os mesmos autores concluem que a abstração reflexionante é diversamente distinta da abstração empírica, pois é o processo pelo qual adquirimos conhecimento construindo novas estruturas mentais reorganizando elementos tirados das estruturas mentais prévias.

Diversamente das duas anteriores é a abstração pseudo-empírica. Esta ocorre quando retiramos dos objetos não as suas características observáveis, mas antes, aquilo que nós (sujeitos) lhe colocamos (BECKER, 2014; TERRIBILE, 2019). Com efeito, é por meio dela que o sujeito projeta no mundo dos observáveis aquilo que entende sobre eles (coordenações das ações) (BECKER, 2014). Não temos como deixar de observar que a abstração pseudoempírica senão completamente, é em algum grau, a própria revolução copernicana-kantiana. Por isso destacamo-la.

Podemos agora retomar a discussão sobre a dialética sujeito-objeto e compreendê-la um pouco mais a fundo. Pois bem, sabemos que pelos pressupostos piagetianos do construtivismo, no ato de conhecer o sujeito modifica o objeto, pois lança sobre ele aquilo que pensa sobre ele. Por conseguinte, ao conhecer o objeto o sujeito se modifica, porque aumenta a robustez, a complexidade e a diversidade de seus esquemas de assimilação tornando-se cada vez mais capaz de apreender o mundo em suas notas mais complexas (BECKER, 2001, 2013).

Ademais, devemos lembrar que os esquemas de ação (assimilação e acomodação) são fluxos autorreguladores conduzindo a equilibração. Logo, absolutizar sujeito ou objeto traria complicações conceituais à epistemologia genética, pois não haveria fluxo autorregulador tendo somente um ou outro (PIAGET, 2007).

E, finalmente, esse processo de construção de conhecimento leva o sujeito a autonomia de pensamento (PIAGET, 2007; 2013), algo caro ao construtivismo pedagógico como veremos adiante (PIAGET, 1999). Portanto, é esse um processo consciente em que o sujeito precisa se vê, e contemporaneamente ao se vê, o sujeito se torna objeto diante da sua própria ação de conhecer.

Finalmente, como já dissemos, Piaget admite a existência de fatores congênitos (os esquemas mentais iniciais), as ditas estruturas a priori, que garantem a possibilidade do conhecimento e, consequentemente, o desenvolvimento intelectual do sujeito epistêmico. Mas já dissemos também, que esses esquemas podem se aprimorar ao longo das experiências de vida do sujeito ao longo de toda sua vida (PIAGET, 1977; 2007; 2013). Com efeito, os esquemas 
mentais estão em constante evolução. E diversamente dos esquemas mentais kantianos, eles não são universais e nem estáticos.

\section{MODELO PEDAGÓGICO NÃO-DIRETIVO OU APRIORÍSTICO}

O modelo pedagógico apriorístico é comumente relacionado a uma pedagogia nãodiretiva. Embora a denominação não-diretiva seja bastante usada por professores e teóricos da educação, avaliamos que essa não-diretividade não acontece efetivamente.

Pelo que já dissemos, nos parece natural a essa altura, sugerir que a todo modelo pedagógico haja um sentido de movimento para ocorrência da aprendizagem. No modelo apriorístico, aqui discutido, a aprendizagem é um movimento que parte do aluno em direção ao professor. Epistemologicamente, é do sujeito epistêmico para o objeto de interesse (BECKER, $2001 ; 2013)$.

Já foi dito, também, que no apriorismo o sujeito traz consigo todas as condições que possibilitam a aprendizagem; elas já estão programadas geneticamente, são dadas (prédeterminado ou a priori). Portanto, a aprendizagem seria uma questão de amadurecimento, ou seja, caberia ao sujeito (aluno) apenas esperar pelo tempo certo (maturação biológica) para que seja capaz de trazer à consciência essa nova aprendizagem, enchê-la de conteúdo e significado (BECKER, 2013).

Esse modelo nos parece muito radical, pois minimiza ou desvirtua a importância da educação formal seja como arte, seja como profissão. Ele não dá a devida importância à escola e, ao professor, tampouco (BECKER, 2013).

Ocorre que, se o aluno já possui todas as condições de possibilidade para aprender e, depende expressamente dele para que a aprendizagem se torne visível, não há muito o que a escola e o professor possam fazer. Em um primeiro momento, isto pode sugerir para alguns, que seja fácil pôr este modelo em prática. Entendemos que essa perspectiva está equivocada.

Conforme Becker $(2001 ; 2013)$, esse modelo postula que não cabe à escola e nem ao professor estabelecer temas de estudo, atividades didáticas (mesmo que minimamente estruturadas), objetivos educacionais, critérios de avaliação, entre outras ações de ordem didático-pedagógica.

Entretanto, deve ficar claro conforme nossa discussão anterior, que a não-diretividade do apriorismo, por meio dos esquemas mentais ou estruturas a priori, não postula que o conhecimento já esteja pronto, outrossim, garante a possibilidade do conhecimento e, portanto, na esfera pedagógica, as novas aprendizagens. 
Em Kant não vemos isso muito claramente, seja da leitura de sua obra magna, a Crítica da Razão Pura, ou por meio de seus comentadores como Pascal (2001), por exemplo. Mas em Piaget, essa ponderação aparece a todo instante (PIAGET, 2007).

Este, por exemplo, parece ser o lugar de fala de Marco Antônio Moreira quando chama a atenção para o fato de que centrar a educação no aluno não pode ser sinônimo de nãodiretividade. Com efeito, isso remete a um novo contrato didático cujo fim é responsabilizar o aluno pela própria aprendizagem. "Que ele [o aluno] é o senhor dessa aprendizagem" (MOREIRA, 2011, p. 7).

O apelo ao modelo apriorístico vem da máxima de que é o aluno quem decide, verdadeiramente, se quer aprender (CRATO, 2006). Uma vez que o aluno não tenha intenção ou predisposição para aprender, de nada valerá o material didático, o modelo pedagógico, as estratégias e as metodologias de ensino que, porventura, venham a ser empregadas pelo professor (CRATO, 2006; MOREIRA, 2011). Daí resulta que não adianta insistir em um modelo centrado no professor como o tradicional.

Entendemos que a premissa da aprendizagem centrada no aluno parece descolada da realidade educacional. Além disso, é um modelo que não teve sucesso, como ressaltado por Gaspar (2014). E em relação à aprendizagem que acontece somente ante o interesse do aluno outra premissa do modelo centrado no aluno -, Moreira (2011) argumenta que devemos desassociar aprendizagem significativa, ou a aprendizagem por interesse, como se fossem sinônimas de aprender prazerosamente.

O modelo construtivista com base na epistemologia genética é diverso do modelo apriorístico. Este é centrado no aluno, porém, aquele, centra-se no ato pedagógico, na relação professor-aluno (BECKER, 2013; PIAGET, 1999). De algum modo, do ponto de vista concreto, a dimensão relacional do modelo construtivista parecer ter sido desvirtuada e passou a ser vista como sinônimo de deixar o aluno sozinho no ato de aprender ou aprender por tentativa e erro (BECKER, 2001; 2013; CRATO, 2006; GASPAR, 2014).

A pouca estruturação ou controle por parte do professor das atividades didáticas é diferente da completa ausência de direcionamento didático-pedagógica do modelo apriorista, quando praticado no limite de seus pressupostos. De fato, a pouca estruturação é uma relativização, para menos, quando comparado o modelo construtivista com o tradicional. Todavia, muitos entendem, erroneamente, o construtivismo como um modelo pedagógico centrado no aluno (BECKER, 2001; 2013). 
Assim, em face às argumentações precedentes, concluímos que não se pode reduzir o modelo construtivista (relacional) em um modelo não-diretivo, pois este último minimiza a figura do professor de tal sorte que não há dialética. E, por óbvio, não se reduz o modelo nãodiretivo a um construtivista ou relacional.

\section{CONSIDERAÇõES FinAIS}

Vimos em linhas gerais um breve cotejo entre Kant e Piaget à luz do apriorismo. Fizemos a apresentação do criticismo kantiano, da epistemologia genética, e, demos ênfase ao postulado das estruturas de conhecimento a priori.

Um dos pontos de diferenciação que pudemos observar foi que, embora Piaget reconhecesse Kant como um mestre, ele teve autonomia de pensamento e caracterizou o apriorismo da epistemologia genética como um apriorismo dito biológico, evolutivo, portanto.

Piaget gostava de se ver como epistemólogo genético devido ao caráter eminentemente epistemológico de suas pesquisas. Apesar disso, como é de observação direta, em vários países incluindo-se o Brasil, as teorizações piagetianas encontraram na educação terreno fértil, de modo que, para muitos, Piaget foi um grande pedagogo.

Kant, por seu turno, enfrentou questões de ordem metafísica, ao passo que a sua epistemologia, ou teoria do conhecimento, teve estreita relação mais com a validade do conhecimento, do que com sua construção.

Com efeito, o construtivismo piagetiano, diversamente do kantiano, é um meio termo entre empirismo e apriorismo (inatismo). O sujeito é dotado de estruturas funcionais hereditárias especiais e gerais que lhe permitem conhecer. Todavia, a experiência e o confronto com a empiria são duplamente importantes, tanto para validar o conhecimento adquirido quanto para modificar os esquemas de assimilação incipientes levando, portanto, a acomodação.

Para o construtivismo piagetiano o conhecimento não estando pronto, emerge e se estabelece por meio da dialética sujeito-mundo (objeto) motivada, pois, pela conduta, pelo interesse ou pela ação do sujeito epistêmico. Isso é o que dispara a dialética sujeito-mundo devidamente mediada pela inteligência.

Volvendo-se nossa atenção para o construtivismo kantiano, uma questão que não fica claro é o postulado do sujeito proativo que traz em si, as estáticas e universais formas de sensibilidade e as categorias do entendimento. Consistiria a essa tal proatividade somente adequar o caos de nossas impressões na caixinha da mente mais apropriada valendo-se tão 
somente da imaginação? Ao que parece a resposta é positiva, mas Kant não deixa claro como exatamente a imaginação opera em função disso.

Independente do apriorismo kantiano ou do empirismo, para ambos o conhecimento é sempre algo dado, para o primeiro ele está no sujeito, e, está no objeto para o segundo. Pondo de outro modo num tom quase jocoso, o que temos, em síntese, é uma passividade subjetiva no primeiro e uma passividade objetiva no segundo.

Todavia, a dialética que inere à epistemologia genética supera esta dificuldade além de ser mais rica na explanação dos processos cognitivos recrutados para a aquisição de conhecimento, e que, ao nosso ver, somente o modo de conhecer de abstração pseudo-empírica já encerra em alguma medida o construtivismo kantiano.

Muitos são os afastamentos e as aproximações possíveis entre Immanuel Kant e Jean Piaget. Neste ensaio fizemos o recorte no que concerne as estruturas a priori do conhecimento, pois nosso interesse aqui foi de explicitar o quanto a epistemologia ilumina e dirige a concepção pedagógica e nossa prática didática.

Portanto, em atenção às questões postas na introdução deste artigo vimos que a resposta para a questão (b), que procura saber se é possível reduzir construtivismo de Kant ao de Piaget, e vice versa, é negativa. Com efeito, não é possível reduzir um apriorismo a outro embora a abstração pseudo-empírica da epistemologia genética abarque, em certo grau, a revolução copernicana-kantiana.

A questão (a), referente às diferenças entre os construtivismos dos autores estudados, pelo exposto nas seções anteriores, vimos que a significação de a priori é tomado de modo diferenciado para os pensadores supraditos. A natureza das estruturas de conhecimento a priori são estáticas para Kant e dinâmicas para Piaget.

Para Kant as estruturas a priori do conhecimento estão no próprio sujeito, portanto é um apriorismo lógico, na medida em que é uma conclusão que se chaga após analisar racionalmente as experiências. No apriorismo kantiano a estrutura cognitiva é comum a todos os seres humanos, fato que garante a objetividade empírica do conhecimento.

Para Piaget esses esquemas encontram-se programados geneticamente na estrutura cerebral do sujeito e se desenvolvem ao longo de toda a vida de acordo com os quatro forçantes: maturação (interno), experiência com objetos reais (externo físico), transmissão cultural (externo social) e a equilibração (autorregulação de fluxos entre fatores internos e externos).

Em relação a pergunta (c), mostramos o quão pode ser inconveniente um modelo pedagógico unicamente iluminado pelo criticismo ou construtivismo kantiano. Pois, 
desencoraja o seguimento de um currículo, do estabelecimento e do cumprimento de objetivos educacionais. Por conseguinte, vimos também, que esse modelo minimiza (ou desvirtua) o papel do professor, tornando-o facilitador da aprendizagem.

O facilitador nem ensina e nem educa; mas antes, apenas, faz com que o conhecimento que jaz internalizado no sujeito venha à superfície, no tempo do aluno (maturação). Esse não é um bom entendimento do apriorismo. Afinal, ter em si as condições de possibilidades de conhecimento não é sinônimo de que iremos conhecer tudo um dia. Daí emerge a proatividade do sujeito como postulada por Kant. Mas é somente com Piaget que temos a descrição objetiva dos processos cognitivos vivenciados pelo sujeito, que permitem a construção/evolução do conhecimento indo mais simples para o mais complexo.

Além disso, de ante do nosso lugar de fala, discutimos também o quanto esse modelo pedagógico, se visto literalmente, pode ser prejudicial, porquanto complica a relação alunoprofessor, em que toda a afetividade descamba para mera imposição de poder por parte da escola e do professor para regular (reprimir) o elevado grau liberdade concedido aos alunos. Esse não nos parece ser o tipo de escola que queremos.

\section{REFERÊNCIAS}

BECKER, Fernando. Educação e Construção do Conhecimento. $1^{a}$ ed. Porto Alegre: Artmed, 2001.

BECKER, Fernando. A Epistemologia do Professor: o cotidiano da escola. $16^{\mathrm{a}} \mathrm{ed}$. Petrópolis: Vozes, 2013.

BECKER, Fernando. Abstração pseudo-empírica e reflexionante: significado epistemológico e educacional. Schème, Marília, SP, v. 6, n. especial, 2014.

BRASIL. Ministério da Educação (MEC). Secretaria de Educação Fundamental (SEF). Parâmetros curriculares nacionais: introdução aos Parâmetros Curriculares Nacionais. Brasília, DF: MEC, SEF, 1997.

BRASIL. Ministério da Educação (MEC). Secretaria de Educação Básica (SEB). Diretrizes curriculares nacionais para o ensino fundamental /Secretaria de Educação Básica. Brasília, DF: MEC, SEB, 2010.

BRASIL. Base Nacional Comum Curricular (BNCC). Segunda versão revista. Brasília, DF: MEC, CONSED, UNDIME, 2016.

CAStAÑON, Gustavo Arja. O que é construtivismo? Caderno de História e Filosofia da Ciência. Campinas, SP, v. 1, n. 2, 2015.

CRATO, Nuno. O Eduquês em Discurso Direto: uma crítica a pedagogia romântica e construtivista. $11^{\text {a }}$ ed. Lisboa: Gradiva, 2006. 
GASPAR, Alberto. Atividades Experimentais no Ensino de Física: uma nova visão baseada na teoria de Vigotski. $1^{\mathrm{a}}$ ed. São Paulo: Livraria da Física, 2014.

GIL, Antônio Carlos. Como Elaborar Projetos de Pesquisa. 5ª ed. São Paulo: Atlas, 2010.

KANT, Immanuel. Crítica da Razão Pura. Tradução de Valério Rohden e Udo Baldur Moosburger. $2^{a}$ ed. São Paulo: Abril Cultural, 1983. (Os Pensadores).

MONDIN, Battista. Curso de Filosofia. Volume 2. 11ª Ed. São Paulo: Paullus, 2009.

MOREIRA, Marco Antônio. Abandono da narrativa, ensino centrado no aluno e aprender a aprender criticamente. Ensino, Saúde e Ambiente, Niterói, RJ, v. 4, n. 1, 2011.

PASCAL, Georges. O Pensamento de Kant. Tradução de Raimundo Vier. $7^{a}$ ed. Petrópolis: Vozes, 2001.

PIAGET, Jean. Seis Estudos de Psicologia. Tradução: Maria Alice Magalhães D’ Amorim e Paulo Sérgio Lima Silva. 24a ed. Rio de Janeiro: Forense Universitária, 1999.

PIAGET, Jean. La Naissance de l'intelligence chez L'enfant. Paris: Delachaux et Niestlé, 1977.

PIAGET, Jean. A representação do Mundo na Criança. Tradução de Adail Ubirajara Sobral. $3^{\text {a }}$ ed. Aparecida: Ideias \& Letras, 2005.

PIAGET, Jean. Epistemologia Genética. Tradução de Álvaro Cabral. $3^{\text {a }}$ ed. São Paulo: Martins Fontes, 2007.

PIAGET, Jean. A Psicologia da Inteligência. Tradução de Guilherme João de Freitas Teixeira. Petrópolis: Vozes, 2013.

SENA, Daniel Richardson de Carvalho; SILVA, Victor Leandro da. Os limites do Conhecimento Humano na Filosofia de Immanuel Kant. Kalagatos, Fortaleza, CE, v. 12, n. 23, 2015.

SILVA, Victor Leandro da; SENA, Daniel Richardson de Carvalho. Kant e Adorno: educação e autonomia. Saberes, Natal, RN, v. 1, n. 11, 2015.

TERRIBILE, Mayara de Andrade. A relação entre a crítica de Jean Piaget às epistemologias clássicas e a explicação do processo de produção de novidade. Schème, Marília, SP, v. 11, n. $1,2019$.

VAYSSE, Jean-Marrie. Vocabulário de Immanuel Kant. Tradução de Claudia Berliner. São Paulo: Martins Fontes, 2012.

Recebido em: 3 de julho de 2020.

Aprovado em: 14 de dezembro de 2020. 